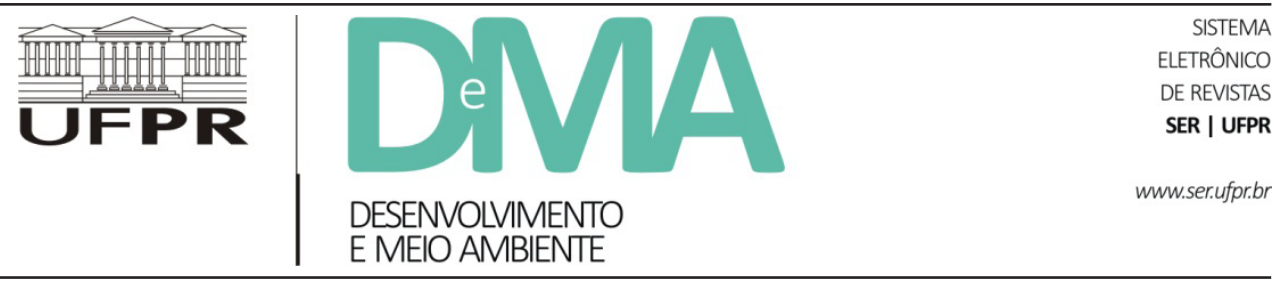

\title{
Para onde estamos indo? Uma avaliação do plano diretor do Município de Florianópolis para o entorno da Estação Ecológica de Carijós
}

\section{Where are we going to? An Evaluation of Florianópolis City Master Plan for the Surroundings of Carijós Protected Area}

\author{
Apoena Calixto FIGUEIROA ${ }^{1 *}$, Marinez Eymael SCHERER ${ }^{1}$ \\ ${ }^{1}$ Programa de Pós-graduação em Geografia, Universidade Federal de Santa Catarina (UFSC), Florianópolis, SC, Brasil. \\ *E-mail de contato: apoenafigueiroa@gmail.com
}

Artigo recebido em 11 de junho de 2016, versão final aceita em 11 de agosto de 2016.

RESUMO: As zonas costeiras e seus ecossistemas associados sofrem pressões pelos usos e atividades humanas, levando a alterações importantes destes ambientes. Estas alterações levam à perda de serviços ecossistêmicos e seus benefícios, afetando as populações que dependem direta ou indiretamente destes serviços. Sendo assim, a gestão costeira integrada deve ocupar-se em manter e melhorar o bem-estar humano, prevenindo a alteração dos ambientes costeiros com diversos instrumentos operativos e estratégicos. Dentre esses instrumentos, destacam-se os Planos Diretores Municipais, os quais devem absorver os princípios de um planejamento urbano que conserve ou recupere as funções dos sistemas ambientais que dão suporte a estes serviços e benefícios. Conforme o plano de manejo da Estação Ecológica de Carijós, as áreas de vegetação de restinga, manguezal e banhado no seu entorno cumprem um importante papel de amortecimento dos impactos causados pela urbanização à biota. Portanto, é importante comparar a atual proposta de plano diretor do município para esta área com as restrições às ocupações previstas na legislação ambiental e quantificar as potenciais perdas ecossistêmicas e dos serviços associados. Este trabalho se baseou em levantamento de vegetação, cursos d'água e ocupação do solo existente, correlacionando as restrições legais. Os resultados foram comparados com dados do plano diretor para o município de Florianópolis. Foram então analisados os ecossistemas possivelmente atingidos e os serviços ecossistêmicos a eles associados, por meio de sobreposição de imagens e mapas. Com base nos resultados, conclui-se que o plano diretor encontra-se em desacordo com a legislação ambiental em vigor, assim como com as legislações que envolvem prevenção às catástrofes naturais. Da análise dos serviços ecossistêmicos relacionados aos diversos ambientes potencialmente impactados, é possível vislumbrar a perda destes serviços, levando a um cenário impactante não só à biodiversidade, mas também ao bem-estar social.

Palavras-chave: unidade de conservação; serviços ecossistêmicos; plano diretor; ilha de Santa Catarina. 
ABSTRACT: Coastal areas and their associated ecosystems are under pressure by human uses and activities, leading to major changes in these environments. Those changes have led to loss of ecosystem services and benefits affecting populations that depend directly or indirectly on these services. Thus, the integrated coastal management should work towards maintenance and improvement of human well-being, preventing coastal environment impacts with operating and strategic instruments. One of these instruments might be the Municipal Urban Plan, which should absorb the principles of urban planning conservation or, in some cases, recover environmental functions of the systems supporting services and benefits. According to the management plan for Carijós Protected Area, the surrounding areas of salt marsh, mangroves and coastal vegetation play an important role as a buffer zone to the impacts of urbanization. Therefore, it is important to compare the current proposal of occupation for this area according to the Florianópolis' urban plan, to the use restrictions provided by the environmental legislation. It is also important to quantify potential ecosystem and its associated service losses resulting from the zoning proposed by the urban plan. This work was based on a survey of vegetation, waterways and occupation, and the legal restrictions applied. The results were compared to the Florianópolis' urban plan. Ecosystems and its ecosystem services were analyzed regarding the possibly of impacts due to the implementation of the plan, using map and image overlap. Based on the results it is concluded that the urban plan is at odds with the environmental legislation, as well as the laws involving prevention of natural disasters. From the analysis of ecosystem services related to the various environments potentially affected by the urban plan a catastrophic scenario can be predicted, not only to the biodiversity, but also to the social welfare.

Keywords: protected area; ecosystem services; master plan; Santa Catarina Island.

\section{Introdução}

As zonas costeiras e seus ecossistemas associados sofrem pressões pelos usos e atividades humanas, levando a alterações importantes destes ambientes (Barragán, 2014). Estas alterações vêm levando à perda de serviços ecossistêmicos e seus benefícios, afetando as populações que dependem direta ou indiretamente destes serviços (Scherer \& Asmus, 2016).

Sendo assim, a gestão costeira integrada deve ocupar-se em manter e melhorar o bem-estar humano, prevenindo esta alteração dos ambientes costeiros com diversos instrumentos operativos e estratégicos (Barragán, 2014). Dentre esses instrumentos, em nível local, destacam-se os Planos Diretores Municipais, os quais devem absorver os princípios de um planejamento urbano que conserve ou, em alguns casos, recupere as funções dos sistemas ambientais que dão suporte a estes serviços e benefícios.
Dentre estes ambientes costeiros de importância para o bem-estar humano, a Mata Atlântica é considerada um hotspot mundial, sendo uma das áreas mais ricas em biodiversidade e mais ameaçadas do planeta (Myers et al., 2000). Conforme a Constituição Federal de 1988 (Brasil, 1988b), é considerada patrimônio nacional, sendo composta por diversas fitofisionomias, que incluem as florestas ombrófilas densa, aberta e mista, as florestas estacionais decidual e semidecidual, os campos de altitude, os mangues e as restingas.

Conforme a Fundação SOS Mata Atlântica e o Instituto Nacional de Pesquisas Espaciais (INPE) (2016), hoje restam 8,5\% de remanescentes florestais acima de 100 hectares do que existia originalmente e $12,5 \%$ dos fragmentos acima de 3 hectares, sendo que nessa pequena e fragmentada área restante estão presentes mais de $5 \%$ das espécies de vertebrados do mundo e cerca de $5 \%$ da flora mundial. Como um dos principais fatores de 
pressão e ameaça a esse bioma, tem-se a expansão urbana sem planejamento adequado.

Neste contexto, a Estação Ecológica de Carijós (ESEC Carijós) se situa na região noroeste da Ilha de Santa Catarina, inserida no Bioma Mata Atlântica, possuindo duas glebas com vegetação muito bem preservada, com predominância de ambientes de manguezal, com pequenos trechos de vegetação de restinga (IBAMA, 2003), representando uma área verde de proporções significativas no contexto de acelerado processo de urbanização de Florianópolis. A unidade de conservação (UC) protege importante área do ecossistema de manguezais da Ilha de Santa Catarina, limite sul de sua distribuição na costa brasileira. Da mesma maneira, as áreas de restinga arbórea, ecossistema associado da Mata Atlântica mais ameaçado das regiões sul e sudeste do Brasil (Falkenberg, 1999), está presente nesta UC e seu entorno. A ESEC Carijós abriga ainda espécies ameaçadas de extinção, além de espécies já bastante raras na Ilha de Santa Catarina, sendo área de pouso, descanso e alimentação de diversas espécies de aves migratórias. Além disso, contribui na manutenção do estoque de peixes de valor comercial e exporta nutrientes para as baías Norte e Sul da Ilha de Santa Catarina (IBAMA, 2003).

Ainda conforme o plano de manejo da unidade de conservação (IBAMA, 2003), as áreas de vegetação de restinga, manguezal e banhado no entorno da ESEC Carijós cumprem um importante papel de amortecimento dos impactos causados pela urbanização à biota da UC. Nesse contexto, a Zona de Amortecimento da ESEC Carijós e seu zoneamento têm como principal objetivo permitir usos ambientalmente mais adequados ou mesmo restritos nas áreas que se mostrarem essenciais a um amortecimento dos impactos à unidade de conservação (IBAMA, 2003). Transpondo esta zona de amortecimento para as divisões do município de
Florianópolis constantes no plano diretor, traduz-se por uma área contida nos distritos de Cachoeira do Bom Jesus, Canasvieiras, Ratones, Santo Antônio de Lisboa e Sede Insular.

O plano diretor de Florianópolis, para sua elaboração, se fundamentou em prognósticos demográficos elaborados com base em metodologia proposta por Campanário (2007). Com base em tal metodologia, a Prefeitura Municipal de Florianópolis (PMF) pôde estimar, por distrito, a população esperada até o ano de 2050 (PMF, 2010), correspondendo a um aumento de $45,88 \%$ em média para os distritos em análise.

Associada às questões ambientais e perdas de serviços ecossistêmicos e seus benefícios, a Política Nacional de Proteção e Defesa Civil (PNPDEC) (Brasil, 2012a) contempla, entre seus princípios fundamentais, as ações de mapeamento e prevenção das áreas suscetíveis a fenômenos e processos do meio físico cuja dinâmica pode gerar desastres naturais, bem como sua integração às demais políticas setoriais, com ênfase às de ordenamento territorial, desenvolvimento urbano e meio ambiente (CPRM $\&$ IPT, 2014), entre as quais se destacam os planos diretores dos municípios.

Conforme essa política nacional, o plano diretor municipal deve conter essas áreas suscetíveis e a aprovação de novos projetos de parcelamento do solo urbano fica vinculada ao atendimento dos requisitos contidos na carta geotécnica de aptidão à urbanização, que deve ser elaborada a partir desse mapeamento. Ou seja, a caracterização do grau de suscetibilidade a determinado processo do meio físico em uma área específica deve pautar as correspondentes medidas de restrição à ocupação, de modo a evitar a formação de novas áreas de risco (CPRM \& IPT, 2014).

Sendo assim, o presente trabalho teve dois objetivos principais: 1) comparar a atual proposta de 
áreas passíveis à ocupação segundo o plano diretor do município de Florianópolis (2014) para a área de entorno da Estação Ecológica de Carijós, com as restrições às ocupações previstas na legislação ambiental; e 2) quantificar e qualificar as potenciais perdas ecossistêmicas e dos seus serviços associados, decorrentes do zoneamento proposto pelo plano diretor.

\section{Material e métodos}

\section{1. Área de Estudo}

A área escolhida para o presente trabalho se localiza na região norte da Ilha de Santa Catarina e está delimitada pela porção insular definida para a Zona de Amortecimento da Estação Ecológica de Carijós (ESEC Carijós), no município de Florianópolis, perfazendo um total de $152 \mathrm{~km}^{2}$. Ela compreende as bacias hidrográficas contribuintes para os manguezais do Saco Grande e de Ratones, ambos componentes da ESEC Carijós, assim como as áreas de preservação permanente (APP) contíguas às bacias, conforme parâmetros abordados por Silva (2005). Como já destacado, tal área compreende parte dos distritos de Cachoeira do Bom Jesus e Sede Insular, e a totalidade dos distritos de Canasvieiras, Ratones, Santo Antônio de Lisboa, conforme divisão do plano diretor do município. A área de estudos pode ser observada na Figura 1.

\subsection{Procedimentos metodológicos}

O presente trabalho partiu dos levantamentos de vegetação, cursos d'água e ocupação do solo oriundos do "Mapeamento de Uso e Ocupação do Solo das Bacias Hidrográficas do Rio Ratones e do
Saco Grande", realizado no âmbito do Subprograma Projetos Demonstrativos - PDA - do Programa Piloto para Proteção das Florestas Tropicais do Brasil, patrocinado pelo Ministério do Meio Ambiente MMA - e pela República Federal da Alemanha/ Kreditanstalt für Wiederaufbau - KFW, denominado "Projeto PDA 066-MA - Implementação do Plano de Manejo da Estação Ecológica de Carijós", coordenado pelo ICMBio e executado pelo Instituto Carijós (Instituto Carijós \& ICMBio, 2009). Para essa tarefa, foram utilizadas como base as imagens de satélite Quickbird de março de 2007. Como parâmetros de classificação da vegetação foram utilizadas as normativas incidentes, incluindo a Lei da Mata Atlântica (Brasil, 2006) e as regulamentações que se referem ao tema (CONAMA, 1994; 1999).

A data da imagem utilizada para a classificação da vegetação (março de 2007) tem fundamental importância, já que é a que sucede de forma mais próxima, dentre as encontradas, a da Lei da Mata Atlântica (dezembro de 2006), que determinou que as áreas de vegetação irregularmente suprimidas após sua promulgação não perderiam sua classificação legal, devendo servir, portanto, como base de análise para as áreas passíveis de ocupação (Brasil, 2006).

Sobre os dados do mapeamento, foram aplicadas as restrições legais incidentes, em especial o Novo Código Florestal (Brasil, 2012b), a Lei da Mata Atlântica e o Plano Diretor de Florianópolis (Florianópolis, 2014), gerando um mapeamento das áreas com restrições à ocupação do solo.

Os dados referentes às restrições legais à ocupação do solo foram comparados com dados vetoriais, acompanhados de tabela de atributos, da proposta de plano diretor para o município de Florianópolis, adquiridos junto ao Instituto de Planejamento Urbano de Florianópolis (IPUF) e disponíveis no sítio oficial da prefeitura municipal 


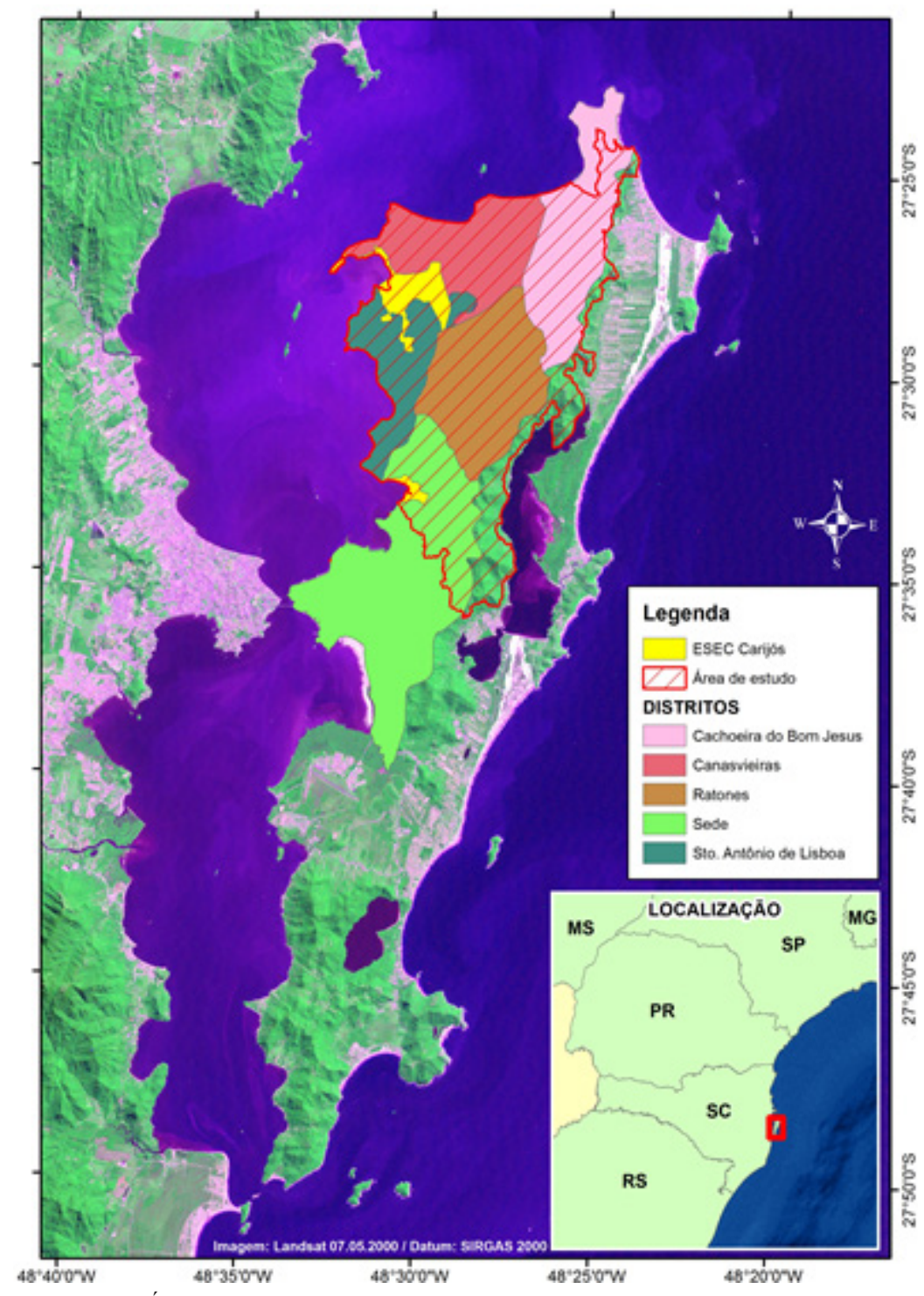

FIGURA 1 - Área de estudo, incluindo os distritos envolvidos na análise.

FONTE: Elaboração própria, a partir de limitação proposta por Silva (2005).

na rede mundial de computadores (PMF, 2014). Como áreas passíveis de serem ocupadas constam no plano diretor as áreas das chamadas "Macroáreas de Uso Urbano" e "Macroáreas de Transição" e podem ser observadas na Figura 2.
Após a comparação entre as áreas com restrições legais à ocupação com as áreas passíveis de serem ocupadas conforme o plano diretor, foram analisados os ecossistemas possivelmente atingidos e quantificadas suas perdas, assim como as dos ser- 


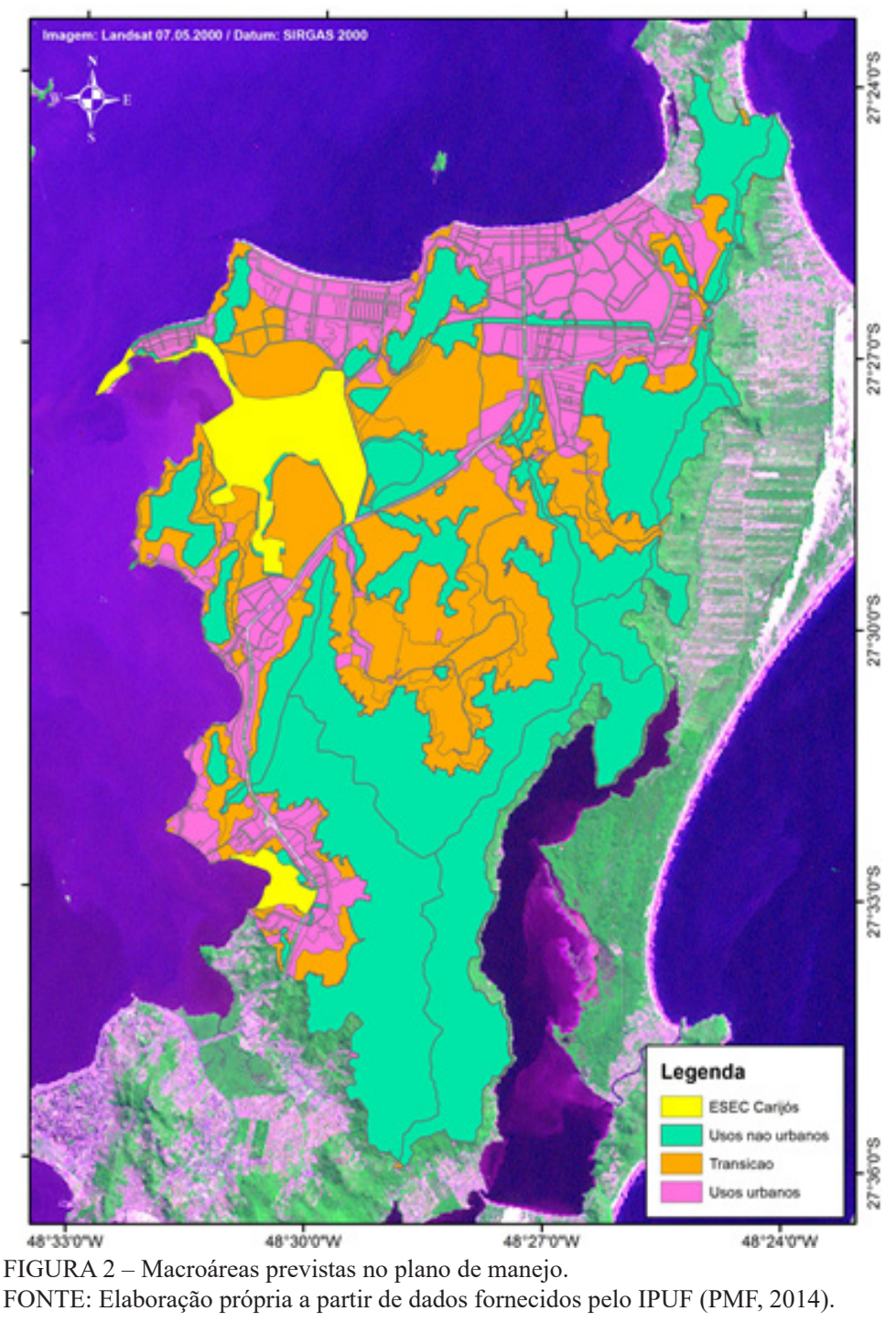

viços ecossistêmicos a eles associados, mantendo-se essa configuração de planejamento urbano. A definição destes serviços ecossistêmicos teve como base o trabalho de Scherer \& Asmus (2016), pesquisa bibliográfica e de dados não publicados do Laboratório de Gestão Costeira Integrada da Universidade de Santa Catarina (LAGECI).
Para a determinação das áreas suscetíveis a fenômenos e processos do meio físico cuja dinâmica pode gerar desastres naturais, foram utilizadas as cartas de suscetibilidade a movimentos gravitacionais de massa e inundações (escala 1:25.000), elaboradas em atenção às diretrizes PNPDEC, pelo Serviço Geológico do Brasil (CPRM) e pelo Institu- 
to de Pesquisas Tecnológicas (IPT), elaboradas para os municípios mais suscetíveis a esses fenômenos (CPRM \& IPT, 2014). Para a análise feita, foram utilizadas somente as áreas com suscetibilidade "alta" à ocorrência dos fenômenos capazes de gerar desastres naturais.

\section{Resultados e discussões}

Conforme define a legislação federal, o principal mecanismo de regramento quanto aos critérios para supressão de vegetação nos diferentes biomas é o chamado Novo Código Florestal (Brasil, 2012b), que traz as definições federais de áreas de preservação permanente (APP), nas quais a urbanização não é permitida, excetuando-se os casos de utilidade pública e interesse social, devidamente autorizados. Analisando-se os parâmetros dessa legislação, foram observadas na região de estudo áreas que não são passíveis de ocupação (estando definidas como APPs), com previsão de uso no plano diretor de Florianópolis. Dentre as APPs mapeadas para uso pelo referido plano diretor encontram-se, principalmente, faixas marginais a cursos d'água, manguezais e restingas com a função de estabilizadoras de mangue.

Além das restrições relativas ao Novo Código Florestal, especificamente para o bioma Mata Atlântica, têm-se restrições diversas quanto ao corte de vegetação incluídas pelos dispositivos da Lei da Mata Atlântica. Essa lei define que, mesmo em áreas urbanas, não são passíveis de desmatamento as formações vegetais em estágio médio, avançado ou primário, quando essas protegerem o entorno de unidade de conservação, abrigarem espécies da flora e da fauna silvestres ameaçadas de extinção ou formarem corredores entre remanescentes de vegetação primária ou secundária em estágio avan- çado de regeneração. Todos esses critérios estão presentes nos remanescentes de vegetação nativa da área em estudo, de forma que todo fragmento de vegetação que não esteja em estágio inicial de regeneração nessa área não deveria ser passível de supressão. Conforme análise espacial efetuada, muitas áreas nessas condições estão previstas para ocupação pelo plano diretor municipal, com destaque para as áreas de restinga arbórea, arbustiva e herbácea.

Além da legislação federal, demais restrições quanto às APPs podem estar previstas em normas estaduais e municipais. Nesse sentido, o plano diretor de Florianópolis, como legislação municipal, prevê áreas a serem consideradas APP em acréscimo àquelas definidas pelo Novo Código Florestal. Dessas áreas destacam-se os banhados e as praias. Em ambos os casos, encontrou-se sobreposição com áreas passíveis de ocupação.

Essas incoerências dos mapas do plano diretor com as áreas de restrição legal poderiam ser vistas como falhas no mapeamento que seriam ajustadas nos casos em particular, porém, o texto da lei do plano diretor é bem claro ao dizer que as restrições de APP federais serão assim respeitadas somente quando essas se encontrarem delimitadas nos mapas de zoneamento (Florianópolis, 2014). Quanto às APPs acrescidas pela legislação municipal, mesmo estando conceitualmente descritas no plano diretor, só nos casos “cuja proteção tenha sido instituída através de classificação dos mapas do zoneamento das leis anteriores" elas seriam protegidas. E, se não estiverem demarcadas nos planos diretores anteriores, seriam protegidas

as áreas classificadas como APP em acréscimo às demarcações do Plano Diretor de 1985 e 1997 ou por atos subsequentes e necessitam do referendo de comissão de avaliação designada pelo Poder Executivo 
Municipal e formada por representantes da SMDU, IPUF, FLORAM e Procuradoria Geral do Município (PGM), submetida à deliberação da Câmara Municipal de Florianópolis (Florianópolis, 2014).

Ou seja, além da necessidade de constarem nos mapeamentos, as áreas restritas à ocupação deverão ter um crivo institucional e político, que acaba por eliminar os critérios técnicos e de impessoalidade.

Embora tal situação corresponda a uma clara ilegalidade e até inconstitucionalidade, na prática acaba por propiciar o estabelecimento de ocupações irregulares amparadas pelo poder público municipal. Esta situação pode se estabelecer, uma vez que as consultas de viabilidade e alvarás para construções são emitidas de acordo com o plano diretor. Tais situações, em alguns casos, são revertidas judicialmente por ações promovidas pelos órgãos de controle e de outras esferas do poder público, porém, na maioria das vezes, acabam por prevalecer o fato consumado e a presunção de inocência do cidadão que agiu de boa-fé, consultando e se amparando nas autorizações municipais. Mesmo nestes casos, os danos ambientais não costumam ser revertidos.

Entre as áreas destinadas à urbanização e as áreas não passíveis de ocupação, o plano diretor definiu "Macroáreas de Transição", que são compostas pelas áreas denominadas por Área de Preservação com Uso Limitado (APL), Área Residencial Rural (ARR) e Área de Urbanização Especial (AUE). Porém, não consta no texto do plano diretor nenhuma restrição quanto ao corte da totalidade da vegetação nativa nessas áreas, sendo que em uma tabela anexa só se encontra uma taxa máxima de impermeabilização do solo de $15 \%$ para as APL e $25 \%$ para as ARR, sendo que as AUE não possuem qualquer limitação neste quesito. Complementarmente, nada aponta que as áreas permeáveis das APL e ARR devam ser compostas por vegetação nativa, essas podendo ser gramadas, jardinadas, cobertas de britas ou material semelhante, ou mesmo representadas por solo exposto. Não é possível, portanto, garantir que qualquer porcentagem de remanescentes de vegetação nativa seja mantida nas ditas "Macroáreas de Transição", já que somente nas chamadas "Macroáreas de Usos não Urbanos" existem restrições quanto à supressão dessa vegetação.

As restrições conflitantes com o plano diretor estão na Figura 3, a qual aponta as diferentes formações vegetais e ambientes que deveriam ser preservados e as áreas urbanizáveis do plano diretor de Florianópolis (2014).

Quando se analisa também as questões relacionadas à suscetibilidade e riscos a desastres naturais vemos que, no caso do plano diretor do município de Florianópolis, não existe nenhuma área mapeada objetivando evitar essas situações, ou mesmo qualquer menção a isso nas diretrizes vinculadas ao plano diretor.

É importante destacar que o Estado de Santa Catarina figura entre os mais atingidos por desastres naturais no país, associados, principalmente, a movimentos gravitacionais de massa nas encostas e inundações. Nesse contexto, o município de Florianópolis teve um total de 72 registros de inundações e 32 registros de movimentos gravitacionais de massa entre 1980 e 2013 (UFSC, 2014). Essa situação de omissão torna o atual mapeamento um instrumento irresponsável quanto aos riscos de acidentes relacionados a fenômenos naturais.

$\mathrm{Na}$ Figura 4, observam-se as áreas com suscetibilidade "alta" à ocorrência dos fenômenos capazes de gerar desastres naturais que se encontram em conflito com áreas ocupáveis do plano diretor, assim como as áreas ocupáveis, subtraindo-se também as áreas legalmente restritas. 


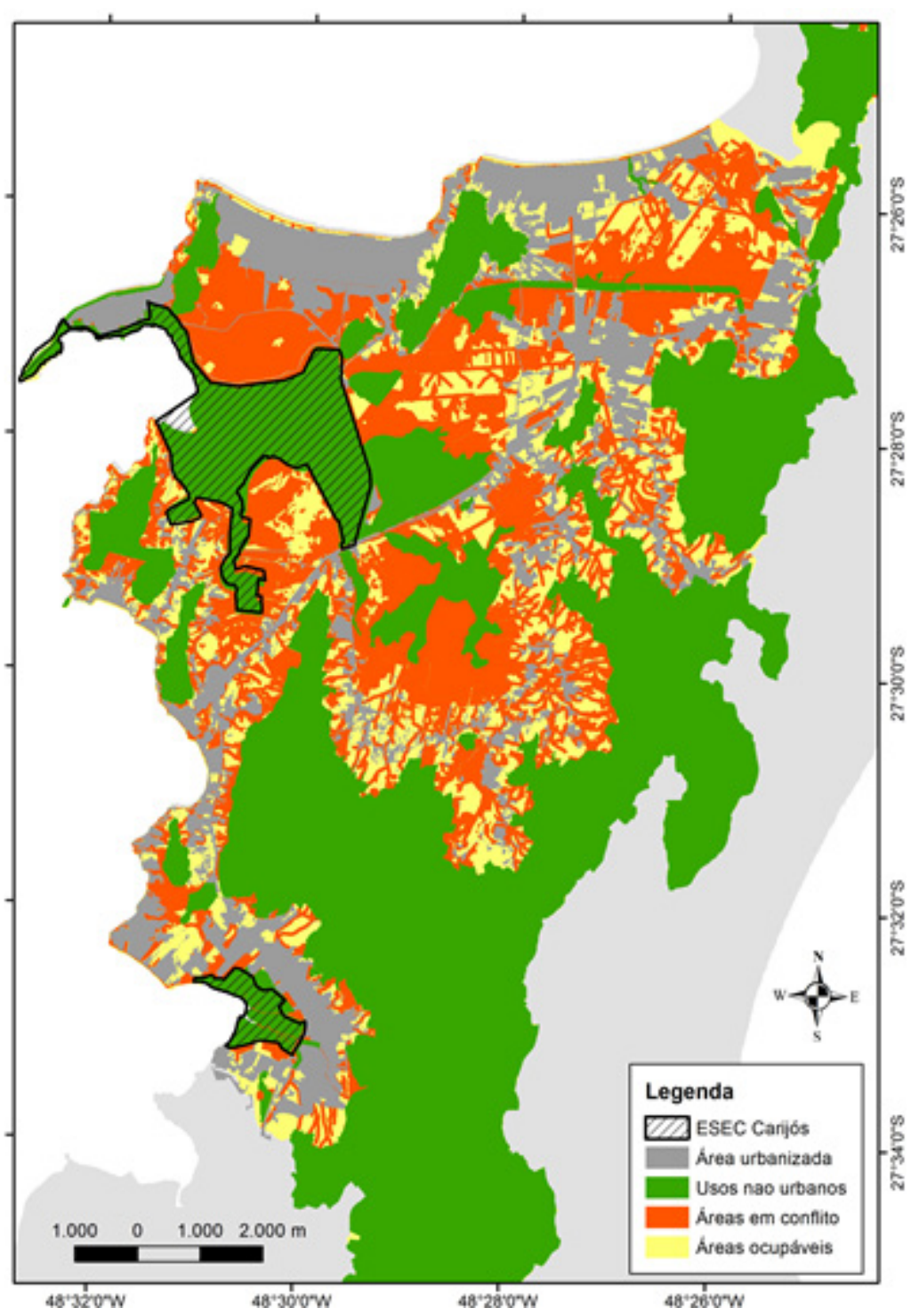

FIGURA 3 - Áreas restritas em conflito com o plano diretor.

FONTE: Elaboração própria a partir de dados fornecidos pelo IPUF (PMF, 2014) e elaborados pela ESEC Carijós (Instituto Carijós \& ICMBio, 2009).

Embora as cartas de suscetibilidade tenham sido elaboradas em escala (1:25.000), não ideal para o planejamento local, a partir dessas devem ser realizados detalhamentos pelo município. Até que esse detalhamento seja realizado, o mais prudente é que se siga as cartas existentes, respeitando-se o Princípio de Precaução, estabelecido como o $15^{\circ}$ princípio da Declaração do Rio sobre Meio Ambiente e Desenvolvimento (Rio 92), da qual o Brasil é signatário e ratificador (Brasil, 1998). 


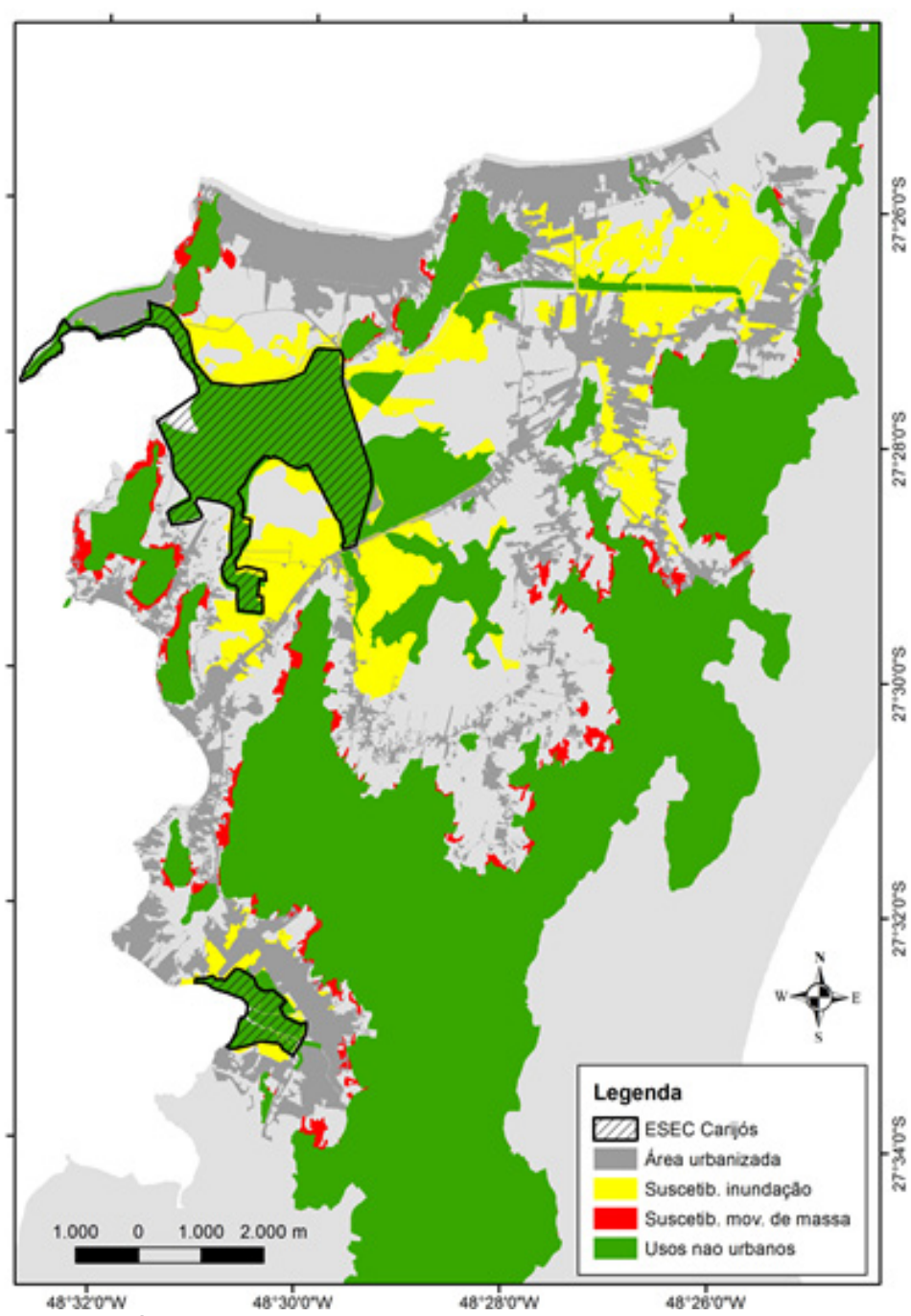

FIGURA 4 - Áreas com suscetibilidade alta à ocorrência de fenômenos naturais capazes de gerar catástrofes e a área passível de ser ocupada.

FONTE: Elaboração própria a partir de dados fornecidos pelo IPUF (PMF, 2016)

e cartas de suscetibilidade a movimentos gravitacionais de massa e inundações

elaboradas por CPRM \& IPT (2014)

3.1. Quantificação de áreas disponibilizadas para ocupação em conflito com a legislação

Conforme o levantamento cartográfico realizado, foram quantificadas as áreas totais relativas às tipologias vegetacionais sujeitas a restrições legais para supressão e as áreas em conflito entre o plano diretor e a legislação vigente, como se pode observar na Tabela 1. 
TABELA 1 - Tipologias vegetacionais legalmente protegidas e conflito com o plano diretor.

\begin{tabular}{|c|c|c|c|}
\hline Tipologia vegetacional & $\begin{array}{c}\text { Total } \\
\text { (em ha) }\end{array}$ & $\begin{array}{l}\text { Conflito } \\
\text { (em ha) }\end{array}$ & $\begin{array}{c}\text { Conflito } \\
(\%)\end{array}$ \\
\hline Floresta Ombrófila Densa - estágio médio e/ou avançado de regeneração & $3.061,45$ & 548,26 & 17,90 \\
\hline Manguezal & 842,52 & 113,14 & 13,42 \\
\hline Manguezal alterado & 214,55 & 147,11 & 68,56 \\
\hline Restinga Arbórea - estágio médio e/ou avançado de regeneração & $1.159,56$ & $1.013,14$ & 87,37 \\
\hline Restinga Arbustiva - estágio médio e/ou avançado de regeneração & 293,19 & 248,38 & 84,71 \\
\hline Restinga Herbácea ou Subarbustiva - vegetação de transição de manguezal & 476,94 & 341,32 & 71,56 \\
\hline Total & $6.245,00$ & $2.591,64$ & 41,50 \\
\hline
\end{tabular}

FONTE: Elaboração própria, com base em levantamento cartográfico.

Todas as tipologias acima descritas possuem proteção determinada pela Lei da Mata Atlântica, sendo que o manguezal, o manguezal alterado e a vegetação de transição de manguezal também encontram proteção no Novo Código Florestal, estando classificadas como APPs, além da vegetação de banhado, que também é considerada APP pelo próprio plano diretor.

É possível observar nesses resultados que as restingas, em todas as suas tipologias, são os ecossistemas mais ameaçados pelo plano diretor, com sua tipologia herbácea de banhado com $91,61 \%$ em conflito com áreas urbanizáveis. O interessante é que essa tipologia é considerada APP pelo próprio plano diretor, que não reflete tal restrição em seu mapeamento.

Além da vegetação acima descrita, têm-se algumas áreas, que aqui se denominarão de unidades ambientais, que possuem restrições à ocupação, independentemente da existência de cobertura vegetal, que são as margens de cursos d'água, consideradas APPs pelo Novo Código Florestal, e as praias, consideradas APPs pelo próprio plano diretor. Observa-se a quantificação das áreas totais e das áreas em conflito com o plano diretor dessas duas unidades ambientais na Tabela 2.
TABELA 2 - Unidades ambientais legalmente protegidas e conflito com o plano diretor.

\begin{tabular}{lccc}
\hline Unidades ambientais & $\begin{array}{c}\text { Total } \\
\text { (em ha) }\end{array}$ & $\begin{array}{c}\text { Conflito } \\
\text { (em ha) }\end{array}$ & $\begin{array}{c}\text { Conflito } \\
(\mathbf{\%})\end{array}$ \\
\hline Praia & 27,03 & 26,33 & 97,38 \\
Margens de cursos & $3.148,69$ & $1.831,80$ & 58,17 \\
d'água & $\mathbf{3 . 1 7 5 , 7 2}$ & $\mathbf{1 . 8 5 8 , 1 3}$ & $\mathbf{5 8 , 5 1}$ \\
Total &
\end{tabular}

FONTE: Elaboração própria, com base em levantamento cartográfico.

Embora se destaquem nesse resultado com $97,38 \%$ de suas áreas em conflito com o plano diretor, as praias historicamente não têm sido alvo de ocupações irregulares permanentes, certamente pelas difíceis condições ambientais para o estabelecimento de edificações. Porém, necessário se faz que as mesmas constem nos mapeamentos municipais.

Outro ponto importante analisado foi o das áreas suscetíveis a fenômenos e processos do meio físico cuja dinâmica pode gerar desastres naturais. Observa-se essa análise na Tabela 3.

Nessa análise, destaca-se principalmente a previsão do plano diretor de ocupação de áreas sujeitas à inundação, com $60,62 \%$ de conflito, situação extremamente complicada quando se pretende prevenir situações envolvendo calamidades sociais, 
principalmente em possíveis cenários futuros de mudanças climáticas e aumento do nível do mar.

TABELA 3 - Áreas suscetíveis a fenômenos e processos do meio físico cuja dinâmica pode gerar desastres naturais em conflito com o plano diretor.

\begin{tabular}{lccc}
\hline \multicolumn{1}{c}{$\begin{array}{c}\text { Áreas suscetíveis a } \\
\text { desastres naturais }\end{array}$} & $\begin{array}{c}\text { Total } \\
\text { (em ha) }\end{array}$ & $\begin{array}{c}\text { Conflito } \\
\text { (em ha) }\end{array}$ & $\begin{array}{c}\text { Conflito } \\
\text { (\%) }\end{array}$ \\
\hline $\begin{array}{l}\text { Suscetibilidade a inundação } \\
\text { Suscetibilidade a }\end{array}$ & $2.683,06$ & $1.626,57$ & 60,62 \\
$\begin{array}{l}\text { movimentação de massas } \\
\text { Total }\end{array}$ & $2.737,72$ & 297,52 & 10,86 \\
\hline
\end{tabular}

FONTE: Elaboração própria, com base em levantamento cartográfico.

Em estudo realizado por Montanari \& Polette (2015), foram avaliados os efeitos da elevação do nível do mar para a bacia do rio Ratones, considerando as projeções do Painel Intergovernamental sobre Mudanças Climáticas (IPCC) para o ano 2100 (IPCC, 2014). No referido estudo, mesmo no cenário mais otimista analisado, 16,5\% (1.658 ha) do território da bacia do rio Ratones será afetado diretamente pela elevação do nível do mar.

Pelos estudos apresentados pelo município (PMF, 2010), para os distritos envolvidos no presente trabalho, temos o crescimento populacional demonstrado na Tabela 4.

TABELA 4 - Previsão de crescimento demográfico para os distritos em tela até o ano de 2050.

\begin{tabular}{lccc}
\hline \multicolumn{1}{c}{ Distrito } & $\mathbf{2 0 1 6}$ & $\mathbf{2 0 5 0}$ & Crescimento (\%) \\
\hline Sede Insular & 242.947 & 363.388 & 49,58 \\
Cachoeira do Bom & 28.936 & 36.115 & 24,81 \\
Jesus & 34.903 & 47.763 & 36,84 \\
Canasvieiras & 6.082 & 10.059 & 65,39 \\
Ratones & 8.373 & 12.192 & 45,61 \\
Santo Antonio de & $\mathbf{3 2 3 . 2 5 7}$ & $\mathbf{4 7 1 . 5 6 7}$ & $\mathbf{4 5 , 8 8}$ \\
Lisboa &
\end{tabular}

FONTE: Elaboração própria, com base em dados da PMF (2010).
Embora o plano diretor tenha vigência de 10 anos, conforme seu texto legal (Florianópolis, 2014), ao se analisar as possibilidades gerais de ocupação, torna-se pertinente vislumbrar um período mais longo. Nesse intuito, com o horizonte do ano de 2050, estima-se um crescimento de $45,88 \%$ da população na área de estudos, com seus consequentes impactos ambientais.

Por fim, com a análise cartográfica realizada, foi possível quantificar as áreas totais previstas no plano diretor que compreendem uso, que são a soma das macroáreas de transição e de uso urbano e as áreas não restritas à ocupação resultantes do presente trabalho, comparando ambas com as áreas atualmente urbanizadas. Como resultado, tem-se o crescimento da área urbana nos dois cenários, conforme pode ser visto na Tabela 5.

TABELA 5 - Crescimento urbano mensurado no cenário do plano diretor e no cenário que exclui as restrições à ocupação.

\begin{tabular}{lcc}
\hline Área urbanizada & Total (ha) & Aumento (\%) \\
\hline Atual & $2.179,26$ & - \\
Ampliação no plano diretor & $4.851,02$ & 222,60 \\
$\begin{array}{l}\text { Ampliação possível, conforme } \\
\text { análise }\end{array}$ & 1295,25 & 59,44 \\
\hline
\end{tabular}

FONTE: Elaboração própria, com base em levantamento cartográfico.

Nessa análise, observa-se a grande discrepância entre o que o plano diretor prevê de ampliação da urbanização $(222,60 \%)$ e o que seria possível diante da legislação e da segurança à ocupação. Tendo em vista as previsões decorrentes do crescimento demográfico, ao menos até 2050 (45,88\%) a necessidade de acomodação da população seria tranquilamente atendida com as áreas passíveis de uso, conforme a análise realizada $(59,44 \%)$. 


\subsection{Ecossistemas, unidades ambientais e serviços ecossistêmicos atingidos}

As áreas em conflito detectadas possuem importância como ecossistemas e como provedoras de serviços ecossistêmicos à sociedade, que sofrerão perdas muitas vezes irreversíveis no caso de o plano diretor se estabelecer por completo. Além da quantificação realizada, para os objetivos do presente trabalho torna-se importante a qualificação dos ecossistemas e serviços ecossistêmicos a serem potencialmente impactados.

\subsubsection{Manguezal}

O manguezal é um ecossistema tipicamente encontrado em situações de interface entre a água doce e os ambientes marinhos, compondo um ecossistema estuarino de extrema peculiaridade e importância biológica. Sua flora é composta por espécies herbáceas, arbustivas e arbóreas, de diferentes famílias, que compartilham de características fisiológicas e adaptações especiais que permitem sua existência em áreas alagadas, salinas, com baixa taxa de oxigênio e de substratos inconsolidados (Schaeffer-Novelli et al., 2000).

Além de historicamente serem ameaçados por aterros e ocupações, por se encontrarem normalmente junto à foz de rios, esses ecossistemas são extremamente contaminados por poluição de toda natureza, situação que se evidencia em todos os manguezais da Ilha de Santa Catarina.

A destruição dos manguezais, segundo Duke et al. (2007), além da perda da sua extraordinária capacidade de produtividade primária, prejudica sua característica de agir como um sumidouro de $\mathrm{CO}_{2}$ atmosférico e como uma fonte essencial de carbono oceânico. Nessa situação, ainda segun- do os autores, o suporte que os ecossistemas de manguezal provêm aos terrestres, bem como às cadeias tróficas marinhas, estaria perdido, afetando negativamente importantes setores, como a pesca. Destacam ainda que seu declínio põe em perigo toda fauna dependente dos manguezais e suas relações ecológicas, bem como benefícios físicos, como a proteção do leito dos oceanos contra os impactos do assoreamento por sedimentos provenientes dos rios, ou a protecção das comunidades costeiras da elevação do nível do mar e tempestades. Por fim, ainda destacam que comunidades humanas que vivem dentro ou perto de manguezais perderiam o acesso a fontes de alimentos essenciais.

\subsubsection{Vegetação de restinga}

Conforme a definição legal,

\begin{abstract}
entende-se por restinga um conjunto de ecossistemas que compreende comunidades vegetais florísticas e fisionomicamente distintas, situadas em terrenos predominantemente arenosos, de origens marinha, fluvial, lagunar, eólica ou combinações destas, de idade quaternária, em geral com solos pouco desenvolvidos. Estas comunidades vegetais formam um complexo vegetacional edáfico e pioneiro, que depende mais da natureza do solo que do clima, encontrando-se em praias, cordões arenosos, dunas e depressões associadas, planícies e terraços (Brasil, 1996).
\end{abstract}

Segundo Falkenberg (1999), principalmente em função da proximidade das restingas com os povoamentos e cidades, pela maior facilidade de ocupação das restingas e pela extremamente reduzida velocidade e capacidade de regeneração em relação às florestas de encostas, tudo isso agravado pela grande expansão imobiliária que envolve as últimas áreas de restinga intactas do estado de Santa Catarina, levou a uma situação desesperadora e ex- 
tremamente preocupante quanto ao futuro imediato destes ecossistemas no Estado. Ainda segundo o autor, todas essas razões tornam a restinga a mais destruída e ameaçada das formações vegetacionais das regiões sul e sudeste do Brasil.

No caso das restingas no entorno da ESEC Carijós, essas abrigam diversas espécies da fauna ameaçadas de extinção, com destaque às aves, conforme os trabalhos de Efe et al. (2007) e Vieira et al. (2014), que identificaram na região as espécies Spizaetus tyrannus (Wied, 1820), Rallus longirostris (Boddaert, 1783), Ramphocelus bresilius (Linnaeus, 1766), Conirostrum bicolor (Vieillot, 1809), Tangara peruviana (Desmarest, 1806) e Sporophila frontalis (Verreaux, 1869), todas ameaçadas de extinção, conforme as listas oficiais.

As vegetações de restinga oferecem um serviço ecossistêmico bastante importante em sua função de fixação de dunas e cordões arenosos costeiros, além da sua importância com relação à biodiversidade, valor paisagístico, refúgio e berçário de fauna terrestre e proteção ambiental contra erosão costeira, funcionando como uma barreira natural e contribuindo para a retenção de sedimentos. A preservação deste ecossistema possibilita ainda, em alguns casos, a provisão de recursos ornamentais, produção de alimentos e serviços associados ao ecoturismo (Oliveira, 2015).

É importante salientar que esse ecossistema, em todas as suas fitofisionomias, seria praticamente eliminado do norte da Ilha com a implantação da atual proposta do plano diretor, conforme as quantificações feitas pelo presente trabalho.

\subsubsection{Floresta Ombrófila Densa}

A Floresta Ombrófila Densa Atlântica, ou Mata de Encosta Atlântica, é a formação vegetal que ocorre nas regiões litorâneas do Brasil, sob influên- cia das massas de ar úmidas, com alta pluviosidade o ano todo, principalmente nas encostas de solo fértil. Estudos no sul da Bahia e norte do Espírito Santo, promovidos por Thomas et al. (1998), mostram que essa é uma das formações que possuem espécies vegetais com maior grau de endemismo.

Na Ilha de Santa Catarina, embora outrora esse ecossistema tenha sido extremamente suprimido devido a atividades de agricultura e pecuária (Caruso, 1990), hoje se observa um cenário bem diferente, onde em grande parte dos morros que compõem a dorsal da ilha encontra-se esse ecossistema em avançado estágio de regeneração.

Estudos em ecologia de paisagem mostram que a degradação de áreas naturais de florestas como as encontradas nas encostas da Ilha de Santa Catarina estão relacionadas com o aumento da erosão do solo e da deterioração da qualidade da água (Lee et al., 2009). Quando se retira as matas de encosta, beneficia-se a erosão pluvial decorrente do escoamento superficial concentrado, facilitado pela ausência de vegetação (CPRM \& IPT, 2014). Também se destaca o papel das matas de encosta no balanço de recursos hídricos (superficiais e subsuperficiais), no ecoturismo, na manutenção da paisagem e no lazer da sociedade, além do seu inestimável valor ecológico.

\subsubsection{Zonas úmidas (banhados e áreas de transição entre restinga e manguezal)}

Conforme conceitua a legislação, "as zonas úmidas são áreas de pântano, charco, turfa ou água, natural ou artificial, permanente ou temporária, com água estagnada ou corrente, doce, salobra ou salgada, incluindo áreas de água marítima com menos de seis metros de profundidade na maré baixa" (Brasil, 1996). A legislação citada promulgou a Convenção sobre Zonas Úmidas de Importância Internacional, 
especialmente como Hábitat de Aves Aquáticas, conhecida como Convenção de Ramsar, que destaca que essas áreas possuem funções ecológicas fundamentais enquanto reguladoras dos regimes de água e enquanto hábitats de flora e fauna características, especialmente de aves aquáticas, constituindo ainda um recurso de grande valor econômico, cultural, científico e recreativo de perda irreparável.

Na presente análise, considerou-se como áreas úmidas somente as áreas que, por se encontrarem na porção terrestre insular, estão sujeitas ao zoneamento do Plano Diretor de Florianópolis.

As áreas úmidas, por sua capacidade de reterem água, contribuem para a diminuição das cheias durante os picos de escoamento, reduzindo a necessidade de infraestruturas contra inundações. Além disso, têm fundamental importância no equilíbrio térmico local, na depuração, filtragem e reciclagem de poluentes, na estocagem de água, na assimilação e reciclagem de nutrientes, como berçário e refúgio de diversas espécies da fauna, na produção de alimentos, entre outros (Moraes, 2011; Oliveira, 2015).

As áreas úmidas ainda proporcionam excelentes oportunidades para contemplação da natureza, atividades educativas e, ainda, como inspiração para diferentes manifestações artísticas. Mais de 30\% dos sítios Ramsar têm importância arqueológica, histórica, cultural, religiosa, mística ou artística (Millennium Ecosystem Assessment, 2005).

Resumidamente, segundo Zedler (2003), as áreas úmidas, embora cubram somente $1,5 \%$ da superfície da terra, contribuem com cerca de $40 \%$ dos serviços ecossistêmicos do planeta.

\subsubsection{Matas ciliares}

Localizadas nas margens dos corpos hídricos, as matas ciliares, independentemente do porte herbáceo, arbustivo ou arbóreo, funcionam como barreira física ao aporte de sedimentos e poluentes, regulando a interface entre os ecossistemas terrestres e aquáticos (Kageyama, 1986). Sua manutenção reduz significativamente a contaminação dos rios, nascentes, lagos e demais corpos hídricos por sedimentos e poluentes, transportados por escoamento superficial da água.

Dessa forma, a existência dessa vegetação está intimamente ligada à manutenção da qualidade dos ecossistemas de água doce, estuarinos e marinhos adjacentes, e sua ausência contribui para a contaminação e o assoreamento dos corpos d'água.

A grande maioria dos canais retilinizados da área em estudo drenam águas provenientes das áreas à montante, não se limitando aos episódios de chuva. Em verdade, esses canais ou provêm da alteração de cursos de rios naturais ou substituem reservatórios d'água também naturais. Ou seja, embora hoje essa água flua por um traçado artificial, ela provém de armazenamentos naturais, o que torna esses canais cursos d'água na essência da palavra.

Também é importante considerar que as funções ambientais das APPs de margens de corpos hídricos vão muito além da preservação dos recursos hídricos e da estabilidade geológica, pois agregam funções essenciais para a manutenção da biodiversidade, incluindo a formação de corredores ecológicos que, além de atuarem como hábitat, possibilitam o fluxo gênico entre populações de fauna e flora, imprescindíveis para a sobrevivência das espécies em longo prazo. Ou seja, também é função das APPs atenuar os efeitos da fragmentação de hábitat, que é considerada atualmente uma das principais causas da extinção das espécies.

Como os canais retilinizados em questão se tratam da alteração de elementos hídricos naturais e não da implementação de obras artificiais, estão 
previstas faixas de APP em suas margens, conforme o Novo Código Florestal.

Muitos estudos mostram a importância ecológica e hidrológica das matas ciliares, funcionando como corredores ecológicos e fonte de alimentação para as faunas terrestre e aquática, sendo também essencial na manutenção da qualidade da água, na estabilidade do solo de áreas marginais, na proteção contra assoreamentos, na regularização do regime hídrico do lençol freático e funcionando como filtro do escoamento superficial, protegendo os cursos d'água de poluentes (Salvador, 1987; Reichardt \& Barbosa, 1989).

\subsubsection{Praias}

Nos termos do Plano Nacional de Gerenciamento Costeiro - PNGC, "entende-se por praia a área coberta e descoberta periodicamente pelas águas, acrescida da faixa subsequente de material detrítico, tal como areias, cascalhos, seixos e pedregulhos, até o limite onde se inicie a vegetação natural, ou, em sua ausência, onde comece um outro ecossistema" (Brasil, 1988a). Conforme esse conceito, pode-se compreender que se trata de um ecossistema extremamente dinâmico, existindo em um intervalo espacialmente variável ao longo do tempo entre os ecossistemas marinhos e terrestres, conforme as forças atuantes nesses ambientes.

Conforme Oliveira (2015), a urbanização sobre a paisagem natural das praias pode afetar, além do turismo, a própria comunidade residente, uma vez que o turismo tem sido uma ferramenta importante para o desenvolvimento de Florianópolis. Além disso, segundo a autora, a ocupação intensa das praias compromete a oferta de serviços ecossistêmicos, especialmente aqueles de regulação e suporte, relacionados à recarga de aquíferos, à retenção de sedimentos, ao controle e estocagem de água e à assimilação e reciclagem de poluentes, além de servir como refúgio e/ou berçário marinho e terrestre, dentre outros.

\section{Conclusão}

Com base nos resultados obtidos, conclui-se que o plano diretor encontra-se em desacordo com a legislação ambiental em vigor, assim como com as legislações que envolvem prevenção às catástrofes naturais.

Por outro lado, o plano diretor também não corresponde às necessidades locais relacionadas às previsões de crescimento demográfico, que seria a argumentação esperada em uma proposta envolvendo tamanha interferência em áreas ambientalmente complexas, representando quase o quíntuplo dessa necessidade.

Dessa forma, observa-se a falta de necessidade em ocupar áreas ambientalmente sensíveis da paisagem (mangues, restingas, margens de rios, etc.), já que se ocupando as áreas não ambientalmente sensíveis acomoda-se o crescimento demográfico previsto com boa margem. Estas áreas, além de possuírem grande valor biológico intrínseco (biodiversidade, diversidade genética, relações ecossistêmicas, etc.), também representam considerável valor à sociedade por meio de seus serviços ecossistêmicos (manutenção da paisagem, produção de pescados, estabilidade geológica, etc.).

Da análise dos serviços ecossistêmicos relacionados aos diversos ambientes potencialmente impactados pelo plano diretor, é possível vislumbrar um cenário catastrófico não só à biodiversidade, mas também ao bem-estar social. Nesse cenário, a população local inevitavelmente sentiria grandes perdas em questões locais, como na pesca, no 
turismo, na qualidade das águas, na saúde e nos locais de lazer, além de um aumento na ocorrência de catástrofes, como enchentes, deslizamentos e desestabilizações da linha de costa.

Por mais que estudos futuros possam demonstrar que parte dessas áreas poderia ser utilizada sem maiores consequências ambientais e sociais, o princípio da precaução determina que se adote um zoneamento mais restritivo no presente momento, tendo em vista a provável irreversibilidade da situação e de seus impactos negativos em se adotando o procedimento contrário. Por outro lado, pelas mesmas razões, detectados a campo elementos ambientalmente relevantes e legalmente impeditivos à urbanização não constantes nos mapeamentos do município, os agentes públicos devem usar os meios necessários para impedir qualquer degradação. Dessa forma, ficam descabidas a burocracia e

\section{Referências}

Barragán, J M. Politica, Gestión y Litoral: nueva visión de la gestión integrada de áreas litorales. [S.1: s.n.], 2014.

Brasil. Lei $n^{\circ}$. 7.661, de 16 de maio de 1988. Institui o Plano Nacional de Gerenciamento Costeiro e dá outras providências. Brasília: DOU de 18.05.1988a.

Brasil. Constituição da República Federativa do Brasil de 1988. Brasília: DOU de 05.10.1988b.

Brasil. Decreto Federal $n^{\circ} 1.905$, de 16 de maio de 1996. Promulga a Convenção sobre Zonas Úmidas de Importância Internacional, especialmente como Habitat de Aves Aquáticas, conhecida como Convenção de Ramsar, de 02 de fevereiro de 1971. Brasília: DOU de 17.05.1996.

Brasil. Decreto Federal no 2.519, de 16 de março de 1998. Promulga a Convenção sobre Diversidade Biológica, assinada no Rio de Janeiro, em 05 de junho de 1992. Brasília: DOU de 17.03.1998. a politização previstas no atual plano diretor para determinação de novas APPs.

Por fim, conclui-se com o presente trabalho que levantamentos técnicos e análises conceituais, como as que aqui foram aplicadas, representam ferramentas de grande valia para as políticas de planejamento urbano, em especial da região costeira, demonstrando a importância da conexão entre a academia e os órgãos públicos de planejamento territorial.

\section{Agradecimentos}

Aos colegas do Laboratório de Gestão Costeira Integrada - LAGECI, que tiveram papel fundamental na elaboração do presente trabalho. Aos moradores do Distrito de Ratones e aos colegas da ESEC Carijós, pelo apoio prestado.
Brasil. Lei Federal no 11.428, de 22 de dezembro de 2006. Dispõe sobre a utilização e proteção da vegetação nativa do Bioma Mata Atlântica, e dá outras providências. Brasília: DOU de 26.12.2006.

Brasil. Lei Federal $n^{\circ} 12.608$, de 10 de abril de 2012. Institui a Política Nacional de Proteção e Defesa Civil - PNPDEC; dispõe sobre o Sistema Nacional de Proteção e Defesa Civil - SINPDEC e o Conselho Nacional de Proteção e Defesa Civil - CONPDEC; autoriza a criação de sistema de informações e monitoramento de desastres; altera as Leis $\mathrm{n}^{\text {os }}$ 12.340, de $1^{\circ}$ de dezembro de 2010, 10.257, de 10 de julho de 2001, 6.766, de 19 de dezembro de 1979, 8.239, de 4 de outubro de 1991, e 9.394, de 20 de dezembro de 1996; e dá outras providências.. Brasília: DOU de 11.04.2012. Brasil, 2012a.

Brasil. Lei Federal no 12.651, de 25 de maio de 2012. Dispõe sobre a proteção da vegetação nativa; altera as Leis nos 
6.938, de 31 de agosto de 1981, 9.393, de 19 de dezembro de 1996, e 11.428, de 22 de dezembro de 2006; revoga as Leis nos 4.771, de 15 de setembro de 1965, e 7.754, de 14 de abril de 1989, e a Medida Provisória no 2.166-67, de 24 de agosto de 2001; e dá outras providências. Brasília: DOU de 28.05.2012. Brasil, 2012b.

Campanário, P. Florianópolis: dinâmica demográfica e projeção da população por sexo, grupos etários, distritos e bairros (1950-2050). Florianópolis, 2007. Disponível em: <http://www.pmf.sc.gov.br/sites/planodiretor/index. php? $\mathrm{cms}=$ materiais $+\mathrm{de}+$ apoio $\& \mathrm{menu}=3>$. Acesso em: 06 jun. 2016

Caruso, M. M. L. O desmatamento da Ilha de Santa Catarina de 1500 aos dias atuais. [S.1.]: Editora da UFSC, 1990.

CONAMA - Conselho Nacional do Meio Ambiente. Resolução Conama $n^{\circ} 4$, de 04 de maio de 1994. Define vegetação primária e secundária nos estágios inicial, médio e avançado de regeneração da Mata Atlântica, a fim de orientar os procedimentos de licenciamento de atividades florestais no Estado de Santa Catarina. Brasília: DOU de 17.06.1994.

CONAMA - Conselho Nacional do Meio Ambiente. Resolução Conama n ${ }^{\circ}$ 261, de 30 de junho de 1999. Aprova parâmetro básico para análise dos estágios sucessivos de vegetação de restinga para o Estado de Santa Catarina. Brasília: DOU de 02.08.1999.

CPRM - Serviço Geológico do Brasil; IPT - Instituto de Pesquisas Tecnológicas. 2014. Cartas de suscetibilidade a movimentos gravitacionais de massa e inundações: 1:25.000 (livro eletrônico): nota técnica explicativa. Coordenação: Bitar, O. Y. São Paulo: IPT - Instituto de Pesquisas Tecnológicas do Estado de São Paulo; Brasília, DF : CPRM - Serviço Geológico do Brasil, 2014.

Duke et al. A World Without Mangroves? Science, 317, 41-43, July, 2007.

Efe, M. A.; Azevedo, M. A. G.; Filippini, A. Avifauna da Estação Ecológica de Carijós, Florianópolis-SC. Ornithologia, 2(1), 1-13, 2007.

Falkenberg, D. B. Aspectos da flora e da vegetação secundária da restinga de Santa Catarina, sul do Brasil. Insula Revista de Letras Y Ciencias Humanas, 28, 1-30, 1999. Disponível em: <http://journal.ufsc.br/index.php/insula/ article/view/21771>.
Florianópolis. Lei Complementar $n^{\circ} 482$, de 17 de janeiro de 2014. Institui o plano diretor de urbanismo do município de Florianópolis, que dispõe sobre a política de desenvolvimento urbano, o plano de uso e ocupação, os instrumentos urbanísticos e o sistema de gestão. Florianópolis: Diário Oficial do Município de Florianópolis de 17.01.2014.

Fundação SOS Mata Atlântica; INPE - Instituto Nacional de Pesquisas Espaciais. 2016. Atlas dos remanescentes florestais da Mata Atlântica 2014-2015. São Paulo. Disponível em: $<$ https://www.sosma.org.br>. Acesso em: 06 jun. 2016.

IBAMA - Instituto Brasileiro do Meio Ambiente e dos Recursos Naturais Renováveis. Plano de manejo da Estação Ecológica de Carijós. IBAMA, 2003. Disponível em: $<$ http://www.icmbio.gov.br/portal/unidadesdeconservacao/ biomas-brasileiros/marinho/unidades-de-conservacao-marinho/2251-esec-de-carijos>. Acesso em: maio 2016.

Instituto Carijós - Instituto Carijós Pró-Conservação da Natureza; ICMBio - Instituto Chico Mendes de Conservação da Biodiversidade. Monitoramento da dinâmica da paisagem no entorno da ESEC Carijós. Produto do "Projeto PDA 066-MA - Implementação do Plano de Manejo da Estação Ecológica de Carijós". Florianópolis, 2009. Disponível na biblioteca da sede da Estação Ecológica de Carijós, Florianópolis/SC.

IPCC - Intergovernmental Panel on Climate Change. Climate Change 2014: Synthesis Report. Contribution of Working Groups I, II and III to the Fifth Assessment Report of the Intergovernmental Panel on Climate Change, 2014. Disponível em: $<$ http://www.ipcc.ch/pdf/assessment-report/ ar5/syr/SYR_AR5_FINAL_full_wcover.pdf $>$.

Kageyama, P. Y. Estudo para implantação de matas de galeria na bacia hidrográfica do Passa Cinco visando à utilização para abastecimento público. Piracicaba: Universidade de São Paulo, 1986.

Lee, S. W. et al. Landscape ecological approach to the relationships of land use patterns in watersheds to water quality characteristics. Landscape and Urban Planning, 92(2), 80-89, 2009.

Millennium Ecosystem Assessment. Ecosystems and human well-being: wetlands and water Synthesis. Regions and Cohesion, 13(3), 127-137, 2005. Disponível em: $<\mathrm{http}$ //berghahnjournals.com/view/journals/regions-and-cohesion/1/3/reco010305.xml>. 
Montanari, F.; Polette, M. Efeitos da elevação do nível do mar para a bacia hidrográfica do rio Ratones - Florianópolis/SC. In: Anais do VIII Congresso sobre Planejamento e Gestão das Zonas Costeiras dos Países de Expressão Portuguesa, 2015. p. 1-13.

Moraes, A. R. Indicadores para a caracterização de serviços ambientais de áreas úmidas. Estudo de caso: a área de Proteção Ambiental das Ilhas e Várzeas do Rio Paraná. 2011. 180 f. Universidade de Brasília, 2011.

Myers, N. et al. Biodiversity hotspots for conservation priorities. Nature, 403(6772), 853-858, 2000.

Oliveira, T. C. R. Uso e qualidade das praias arenosas da Ilha de Santa Catarina, SC, Brasil: bases para seu planejamento ambiental. 143 f. Tese (Doutorado em Geografia) - Universidade Federal de Santa Catarina, 2015.

PMF - Prefeitura Municipal de Florianópolis. Plano Municipal Integrado de Saneamento Básico - PMISB: Produto 3 - Diagnóstico Social. Florianópolis, 2010. Disponível em: <http://www.pmf.sc.gov.br/entidades/habitacao/?cms $=$ plano + integrado + de + saneamento + basico $>$. Acesso em: 04 jun. 2016.

PMF - Prefeitura Municipal de Florianópolis. Materiais de apoio ao desenvolvimento do Plano Diretor, 2014. Disponível em: <http://www.pmf.sc.gov.br/sites/planodiretor/ index.php?cms $=$ materiais + de + apoio $\&$ menu $=3>$. Acesso em: 04 jun. 2016.

Reichardt, K.; Barbosa, L. M. Relações água-solo-planta em mata ciliar. Anais do $1^{\circ}$ Simpósio sobre Mata Ciliar. Coordenação de L. M Barbosa. Campinas: Fundação Cargill, 1989. p. 20-24.
Salvador, L. G. Considerações sobre as matas ciliares e a implantação de reflorestamentos mistos nas margens de rios e reservatórios. [S.1.]: CESP, 1987.

Schaeffer-Novelli, Y. et al. Brazilian mangroves. Aquatic Ecosystem Health \& Management, 3(4), 561-570, 2000.

Scherer, M. E.G.; Asmus, M. L. Ecosystem-Based Knowledge and Management as a tool for Integrated Coastal and Ocean Management: A Brazilian Initiative. Journal of Coastal Research, 75(10), 2016.

Silva, R.B.A. Instrumental para definição de Zonas de Amortecimento de Unidades de Conservação: o caso da Estação Ecológica de Carijós-Ibama, Florianópolis/SC. 84 p. Florianópolis/SC, Dissertação (Mestrado em Geografia) - Universidade Federal de Santa Catarina, 2005.

Thomas, W. M. W. et al. Plant endemism in two forests in southern Bahia, Brazil. Biodiversity and Conservation, 7(3), 311-322, 1998.

UFSC - Universidade Federal de Santa Catarina. Elaboração de cartas geotécnicas de aptidão à urbanização frente aos desastres naturais no Município de Florianópolis, estado de Santa Catarina - Relatório Técnico. Departamento de Geociências. Coordenação: Flores, Juan Antonio Altamirano. Florianópolis: UFSC, 2014.

Vieira, B. P. et al. Birds of Estação Ecológica de Carijós, southern Brazil. Check List, 10(5), 1110-1122, 2014.

Zedler, J. B. Wetlands at your service: reducing impacts of agriculture at the watershed scale. Frontiers in Ecology and the Environment, 1(2), 65-72, 2003. 